Editorial

\title{
Editorial: New Forms of Media Work and Its Organizational and Institutional Conditions
}

\author{
Salla-Maaria Laaksonen ${ }^{1, *}$ and Mikko Villi ${ }^{2}$ \\ ${ }^{1}$ Centre for Consumer Society Research, University of Helsinki, Finland \\ ${ }^{2}$ Department of Language and Communication Studies, University of Jyväskylä, Finland \\ * Corresponding author (salla.laaksonen@helsinki.fi)
}

Submitted: 7 December 2021 | Published: 20 January 2022

\begin{abstract}
This thematic issue explores the widening scope of media work and the institutional and organizational conditions that support new forms of media work. The media industry has undergone significant economic, structural, and technological changes during the past few decades, including changing patterns of ownership and digitalization of media production, distribution, and consumption. Simultaneously, practices of media work are adopted also in other industries. The 10 articles in the issue not only focus on the new professional roles and responsibilities emerging in the news media industry but also study the practices of media work in organizations in other fields, such as the music industry and public sector.
\end{abstract}

\section{Keywords}

corporate media; journalism; media industry; media work; news media; organizational communication; organizations; strategic communication

\section{Issue}

This editorial is part of the issue, "New Forms of Media Work and Its Organizational and Institutional Conditions," edited by Salla-Maaria Laaksonen (University of Helsinki, Finland) and Mikko Villi (University of Jyväskylä, Finland).

(C) 2022 by the author(s); licensee Cogitatio (Lisbon, Portugal). This editorial is licensed under a Creative Commons Attribution 4.0 International License (CC BY).

\section{Introduction}

Media, as ubiquitous as it is in our modern world, requires care, labor, and maintenance. Media work, as defined by Deuze (2007), refers to planning and producing media content, products, services, and brands within media organizations. Media work is not limited to journalistic work but includes other activities undertaken by media professionals aimed at advancing the success of media products and services (Malmelin \& Villi, 2017). Studies in the field of media and journalism have acknowledged how the emergence of new digital players and changes in consumers' media behavior have affected media work (Villi \& Picard, 2019). The inclusion of social media in media work (Nielsen \& Ganter, 2018) and other platform-centric practices are occurring in response to the new, digitalized media environment. The increasing competition is pushing media organizations to con- sider engaging in strategic communication and branding activities (e.g., Laaksonen et al., 2019; Malmelin \& Moisander, 2014).

These factors, among many others, have influenced the ways of working and content of work in the media as well as the organizational dynamics in media organizations. Changes are often driven by technological transformation: Media workers are required to have digital competencies (Oberländer et al., 2020) to cope with new technologies; and new professional roles emerge to satisfy the requirements and labor needed to make media content suitable and successful on various new channels, from social media to mobile applications (Cohen, 2019; Karlsen \& Ytre-Arne, 2021). Further, the ongoing economic, structural, and technological changes in the media industry during the past few decades, including changing patterns of ownership and digitalization of media production, distribution, and consumption (Villi 
et al., 2020) and the subsequent constant need to innovate (Küng, 2013), have impelled institutional responses in media organizations. Examples include the development of novel media outlets and processes, from specialized formats to cross-sector collaborations and intraorganizational development networks.

Furthermore, driven by the increasing power of media in society (e.g., Couldry \& Hepp, 2017), forms of media work are emerging in other industries that aim to communicate with their audiences. These include, for example, organizations that strive to produce professional, media-like content as a component of their strategic communication, and communications agencies that produce communication and marketing content for their customers. It could also be argued that the increasing significance of public social media and demands for dialogue require all employees to possess media skills (Pekkala, 2020). These expanding contexts raise the question of what media work is like when it is done outside the media industry and what principles are driving it.

For the issue, we have invited theoretical and empirical articles investigating the changing nature of media work as well as its new institutional environments. The 10 selected articles cover three main themes: new forms of media work in media organizations, emerging forms of social media work, and atypical organizational contexts for media work. In the following sections, we will briefly introduce the articles by theme.

\section{New Forms of Media Work in Media Organizations}

The first four contributions to this thematic issue approach media work in the context of media organizations. First, Mathias-Felipe de-Lima-Santos (2022) explores the nuances of data journalists' professional roles and how they relate to structural aspects of news organizations. The study concentrates on ProPublica, a nonprofit news organization producing investigative journalism and renowned for its data journalism. According to the study, the blurring of traditional professional boundaries and hybrid profiles of media workers can be detected in data journalism: Journalists must expand their competencies to coding and design, whereas non-journalistic professionals must develop writing skills. Such blurring and hybridity are integral to the professional culture at ProPublica, which mirrors the organizational structure.

A similar negotiation and blurring of boundaries can be detected between the journalistic and managerial professional ethos of editors in business newsrooms, as Johanna Suhonen (2022) shows in her article. Business journalism is an appropriate context for studying the junction of two professional discourses of journalism and managerialism. Editors in business journalism tend to absorb managerial tendencies due to their close connections to financial and commercial communities. This subsequently leads to a new hybrid professional ethos that combines managerial practices with journalistic ideals.
Moving on to digital competencies in journalistic work, Salvador Reyes-de-Cózar et al. (2022) conduct a systematic review to examine what the literature suggests about the digital skills that new professionals should acquire in the field of journalism. Such knowledge is important to journalism schools and other academic institutions that educate future journalists. The findings reveal the lack of studies focusing on certain key aspects of digital competence, particularly those related to personal growth, emotional state, and the acquisition of a deep level of digital competence.

The thematic issue then shifts from newsrooms to Mediapolis, a Finnish media cluster that serves as a center and network for media companies and organizations. Mediapolis offers public (non-commercial) and private (commercial) media organizations cross-sector collaboration aimed at shared value creation and co-creative innovation. Sari Virta and Nando Malmelin (2022) explore the management of complexities, organizational tensions, and dualities in such cross-sector collaboration in a media cluster with shared strategic-level aspirations. The article discusses the dynamics of different organizational orientations and business logics, discrepancies between visionary planning and practical actions, and opposing organizational interests in a cluster structure.

\section{Emerging Social Media Work}

The increasing significance of social media has led to calls for a specific new type of media work. Linking media work in news media organizations and the social media context, Mark Badham and Markus Mykkänen (2022) employ a relational approach to media audiences to clarify how news media organizations are engaging their audiences on social media. They draw on public relations theory and conduct a content analysis of Twitter and Facebook posts by nine newspapers in Australia, the US, and the UK. Using this approach, they show that the studied newspapers predominantly use their social media accounts for news dissemination rather than audience engagement.

An opposite perspective to engagement is given in Jessica Edlom's (2022) article, which uses qualitative interviews to explore the adoption of social media in the music industry, where participatory cultural norms are becoming standard in strategic communication. Edlom conceptualizes her findings through the notion of engagement imperative-the constant requirement to produce audience engagement-which affects communication workers' competencies, roles, responsibilities, and identities. Strategic communication, thus, is increasingly also media work, characterized by the logic of engagement enforced by social media platforms and their participatory culture.

Brooke Erin Duffy and Megan Sawey (2022) further seek to theorize the emerging phenomenon of social media work in their article. Social media workerssuch as social media managers, editors, and community 
managers-form a relatively new category of digital laborers. Using interview data, the authors argue that social media work is configured by a visibility paradox: While the main work of social media workers is producing visibility, their labor remains invisible behind branded accounts. By connecting this notion to broader discussions on the gendered valuation of work in the digital economy, the authors show that social media work has a marginal status and is frequently devalued in organizations and by members of the public.

\section{Atypical Organizational Contexts for Media Work}

The last three articles in this thematic issue further expand the boundaries of media work by focusing on media work conducted in organizational settings outside a typical media organization: public sector organizations, a science communication start-up, and a counter-media outlet.

Maria Grafström and Hanna Sofia Rehnberg (2022) explore what happens when journalistic practices and ideas about newsworthiness enter a public sector organization. Their empirical case is VGRfokus, a Swedish county council's digital news channel. The authors use content analysis and interviews to show how VGRfokus balances between bureaucratic and market values, as the channel aims to both inform citizens and brand the organization. To solve this tension, the idea of newsworthiness emerges as a governing principle for what is considered appropriate for the channel. Yet newsworthiness, in this context, is affected by the demand to create a coherent and positive organizational image, thus reflecting patterns similar to the tensions between discourses of journalism and managerialism identified by Suhonen (2022).

We have also witnessed the emergence of entirely novel types of media organizations that aim to find their place in the insecure, digitalizing field of media. In their article, Christopher Buschow et al. (2022) discuss one such example: the Science Media Center Germany (SMC), a non-profit news start-up. The article positions SMC as a repair organization that aims to support high-quality media work to compensate for the deficits in legacy media. The authors show how SMC undertakes field repair activities but also does field advancement by promoting innovation and renewal of journalism. The authors conclude that SMC acts as a prototype organization in science journalism by offering direct contributions to the field but also by demonstrating new ways of working and organizing.

In the final article, Olli Seuri and Kim Ramstedt (2022) turn the analytical gaze to another novel and atypical context of media work: counter-media. They explore how remix theory can be used to analyze the work of these emerging publishers. Using concepts that are crucial to remixing-appropriation and authorshipthe authors provide a theoretical reading of two news cases in the Finnish counter-media MV-lehti. The authors' approach broadens and challenges the underpinning ideas of participatory and democratizing remix culture by arguing that the media work of remix, when appropriated by an anti-democratic media actor, is a means to challenge liberal-democratic ideals. The authors propose that counter-media publishing should be seen as a form of political activism or, in some cases, political media criticism.

\section{Conclusions}

Together, the articles in this thematic issue give a broad view of the widening scope and contexts of media work, ranging from traditional news media to social media brand communication and public sector organizations. The empirical findings draw a complex picture of overlapping roles, shifting practices, as well as tensions in practices and discourses as actors engage in planning, producing, and distributing media content. The emerging actor roles and professions raise questions about the skills and competencies required for media work but also call for completely new ways of organizing - as a unit, as an organization, or in inter-organizational collaboration.

We argue that the concept of media work proves its usefulness in exploring media-related practices across industries. Media work is used for a variety of purposes that are not necessarily journalistic or follow journalistic values. Due to the institutional pressures posed by the developing media field, media work is a practice that becomes increasingly mixed with forms of strategic communication. As several studies in this issue show, this also introduces ethical questions, which will hopefully encourage future research that continues exploring discourses and valuations related to the developing field of media work as well as its uses in society.

\section{Acknowledgments}

We would like to express our gratitude to all the authors who have contributed to this thematic issue as well as to the professional staff at Media and Communication. Our work has been supported by the Helsingin Sanomat Foundation for the Media Work 2030 project.

\section{Conflict of Interests}

The authors declare no conflict of interests.

\section{References}

Badham, M., \& Mykkänen, M. (2022). A relational approach to how media engage with their audiences in social media. Media and Communication, 10(1), 54-65.

Buschow, C., Suhr, M., \& Serger, H. (2022). Media work as field advancement: The case of Science Media Center Germany. Media and Communication, 10(1), 99-109.

Cohen, N. (2019). At work in the digital newsroom. Digital Journalism, 7(5), 571-591. 
Couldry, N., \& Hepp, A. (2017). The mediated construction of reality. Wiley.

de-Lima-Santos, M.-F. (2022). ProPublica's data journalism: How multidisciplinary teams and hybrid profiles create impactful data stories. Media and Communication, 10(1), 5-15.

Deuze, M. (2007). Media work. Polity Press.

Duffy, B. E., \& Sawey, M. (2022). In/visibility in social media work: The hidden labor behind the brands. Media and Communication, 10(1), 77-87.

Edlom, J. (2022). The engagement imperative: Experiences of communication practitioners' brand work in the music industry. Media and Communication, 10(1), 66-76.

Grafström, M., \& Rehnberg, H. S. (2022). Newsworthiness as a governing principle in public sector communication. Media and Communication, 10(1), 88-98.

Karlsen, F., \& Ytre-Arne, B. (2021). Intrusive media and knowledge work: How knowledge workers negotiate digital media norms in the pursuit of focused work. Information Communication and Society. Advance online publication. https://doi.org/ 10.1080/1369118X.2021.1933561

Küng, L. (2013). Innovation, technology and organisational change: Legacy media's big challenges. In T. Storsul \& A. H. Krumsvik (Eds.), Media innovations: A multidisciplinary study of change (pp. 9-12). Nordicom.

Laaksonen, S.-M., Falco, A., Salminen, M., Aula, P., \& Ravaja, N. (2019). Brand as a cognitive mediator: Investigating the effect of media brands as a structural feature of textual news messages. Journal of Product and Brand Management, 28(1), 1-14.

Malmelin, N., \& Moisander, J. (2014). Brands and branding in media management: Toward a research agenda. International Journal on Media Management, 16(1), 9-25.

Malmelin, N., \& Villi, M. (2017). Media work in change: Understanding the role of media professionals in times of digital transformation and convergence. Sociology Compass, 11(7), Article e12494.

Nielsen, R. K., \& Ganter, S. (2018). Dealing with digital intermediaries: A case study of the relations between publishers and platforms. New Media and Society, 20(4), 1600-1617.

Oberländer, M., Beinicke, A., \& Bipp, T. (2020). Digital competencies: A review of the literature and applications in the workplace. Computers and Education, 146, Article 103752.

Pekkala, K. (2020). Managing the communicative organization: A qualitative analysis of knowledge-intensive companies. Corporate Communications: An International Journal, 25(3), 551-571.

Reyes-de-Cózar, S., Pérez-Escolar, M., \& Navazo-Ostúa, P. (2022). Digital competencies for new journalistic work in media outlets: A systematic review. Media and Communication, 10(1), 27-42.

Seuri, O., \& Ramstedt, K. (2022). Remixing news: Appropriation and authorship in Finnish counter-media. Media and Communication, 10(1), 110-119.

Suhonen, J. (2022). Negotiating journalistic professional ethos in Nordic business journalism. Media and Communication, 10(1), 16-26.

Villi, M., Grönlund, M., Linden, C. G., Lehtisaari, K., Mierzejewska, B., Picard, R., \& Röpnack, A. (2020). "They're a little bit squeezed in the middle": Strategic challenges for innovation in US metropolitan newspaper organisations. Journal of Media Business Studies, 17(1), 33-50.

Villi, M., \& Picard, R. (2019). Transformation and innovation of media business models. In M. Deuze \& M. Prenger (Eds.), Making media: Production, practices, and professions (pp. 121-131). Amsterdam University Press.

Virta, S., \& Malmelin, N. (2022). Managing organisational tensions in cross-sector collaboration: The case of Mediapolis. Media and Communication, 10(1), 43-53.

\section{About the Authors}
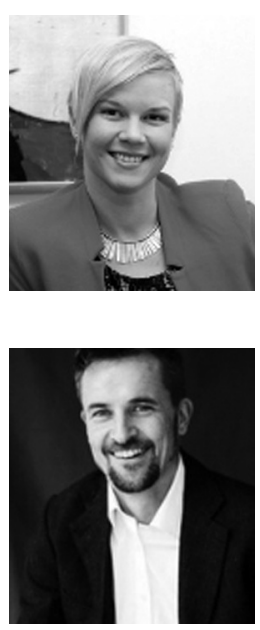

Salla-Maaria Laaksonen (D.Soc.Sc.) is a senior researcher at the Centre for Consumer Society Research, University of Helsinki. Her research areas are technology, organizations, and new media, including social evaluation of organizations in the hybrid media system, the organization of online social movements, and the use of data and algorithms in organizations. She is also an expert in digital and computational research methods.

Mikko Villi (PhD) is professor of journalism in the Department of Language and Communication Studies at the University of Jyväskylä, Finland. An emphasis in his work is on the contemporary context for journalism and media work. Among his research interests are media management, media consumption, media platforms, news media business models, and the digital transition in the media. 